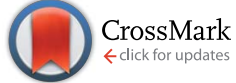

Cite this: RSC Adv., 2015, 5, 36673

\title{
Synthesis of D-A polymers with a disilanobithiophene donor and a pyridine or pyrazine acceptor and their applications to dye- sensitized solar cells $\uparrow$
}

\begin{abstract}
Joji Ohshita, ${ }^{*}$ Yohei Adachi, Daiki Tanaka, Makoto Nakashima and Yousuke Ooyama
New donor-acceptor polymers containing disilanobithiophene (DSBT) as the donor and pyridine or pyrazine as the acceptor with or without a thiophene spacer were prepared. The polymers showed UV-vis absorption maxima at $\lambda_{\max }=488-526 \mathrm{~nm}$, which were red-shifted relative to those of model monomers dithienylpyridine and dithienylpyrazine $\left(\lambda_{\max }=352-375 \mathrm{~nm}\right)$, indicating the efficient conjugation along the polymer chains. A homo polymer of DSBT was also prepared. The DSBT-containing polymers were attached to $\mathrm{TiO}_{2}$ electrodes by immersing the electrodes in the polymer solutions under irradiation (>400 nm) or in the dark. The modified electrodes were applied to dye-sensitized solar cells and a maximal power conversion efficiency of $0.89 \%$ was obtained using the $\mathrm{TiO}_{2}$ electrode thermally modified with a DSBT-pyrazine alternating polymer.
\end{abstract}

Received 19th January 2015 Accepted 10th April 2015

DOI: $10.1039 / c 5 r a 01055 a$

www.rsc.org/advances

\section{Introduction}

Conjugated donor-acceptor (D-A) compounds and polymers are of current interest because they possess optoelectronic functionalities, including photovoltaic properties. ${ }^{1}$ Their broad and red-shifted absorption arising from their low band gaps make it possible to utilize the wide sunlight wavelength range, and their polar structures facilitate photo-induced charge separation in this system. Dye-sensitized solar cells (DSSCs) possess $\mathrm{TiO}_{2}$ electrodes modified with sensitizing dyes. The dyes play a crucial role: electron injection from the photoexcited dyes into $\mathrm{TiO}_{2}$ is the key step in the photocurrent generation. ${ }^{2}$ The dyes usually have a D-A structure and an anchor unit, such as a carboxylic acid or a phosphoric acid, which forms an ester linkage with the $\mathrm{TiO}_{2}$ surface. However, the ester linkages between the sensitizing dyes and the $\mathrm{TiO}_{2}$ surface are generally labile and readily hydrolyzed by moisture, resulting in the detachment of the dyes from the $\mathrm{TiO}_{2}$ surface. Recently, we introduced disilane as a new anchor group that reacts with the $\mathrm{TiO}_{2}$ surface under UV irradiation to form a chemically and thermally stable Si-O-Ti linkage ${ }^{3}$ (Fig. 1(1)). ${ }^{4}$ In fact, irradiation of $\mathrm{TiO}_{2}$ electrodes in solutions of poly(disilanyleneoligothienylene)s (DSxT, $x=5$ or 6 ) led to the formation of polymer-attached electrodes (Chart 1) that could be used for

Department of Applied Chemistry, Graduate School of Engineering, Hiroshima University, Higashi-Hiroshima 739-8527, Japan. E-mail: jo@hiroshima-u.ac.jp; Fax: +81-82-424-5494; Tel: +81-824-424-7743

$\dagger$ Electronic supplementary information available: Experimental procedures of monomer syntheses, NMR spectra of the polymers, and molecular weight-dependent UV-vis spectra of pDSBTTPzT2. See DOI: 10.1039/c5ra01055a
DSSCs. ${ }^{4 a, b}$ However, DSSCs based on DS $x \mathbf{T}$ showed low performance, namely, a maximal power conversion efficiency (PCE) of $0.11 \%$, which is likely due to their narrow absorption band in the visible region. ${ }^{4 a}$ More recently, we prepared disilanylene polymers with conjugated $\mathrm{D}-\mathrm{A}$ systems and used them as sensitizing dyes. ${ }^{4 c, d}$ As expected, the introduction of the D-A structure into the polymer backbone improved DSSC performance due to the red-shifted broad absorption band, and resulted in a higher PCE of $0.25 \%\left(\mathbf{p T}_{2} \mathbf{B t}\right.$ in Chart 1). ${ }^{4 c}$ The introduction of a pyridine (Py) unit into the polymer as the acceptor gave rise to an even higher DSSC performance $\left(\mathrm{PCE}=0.40 \%\right.$ for $\left.\mathbf{p} \mathbf{T}_{\mathbf{4}} \mathbf{P y}\right),{ }^{4 d}$ likely because the Lewis basic Py unit formed a complex with a Lewis acidic site of the $\mathrm{TiO}_{2}$ surface providing secondary bonding that facilitated the dye attachment (Fig. 1(3)). ${ }^{5}$ However, in those systems, the photodegradation of the disilanylene polymer by the addition of silyl radicals generated photochemically from the disilane units to the $\pi$-conjugated units competed with the formation of the

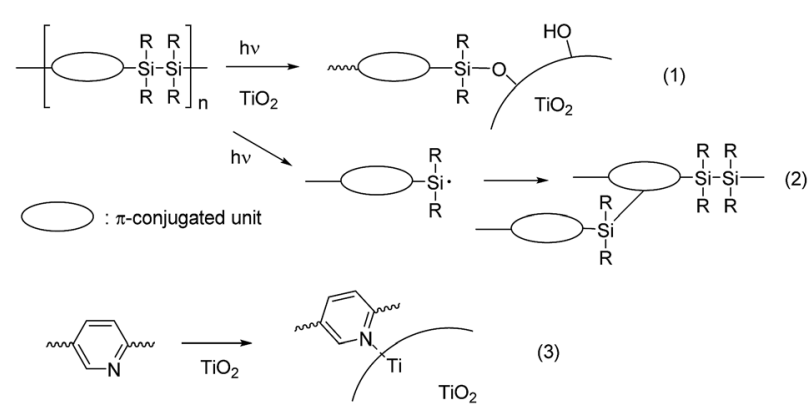

Fig. 1 Attachment of organosilicon polymer to $\mathrm{TiO}_{2}$ surface. 


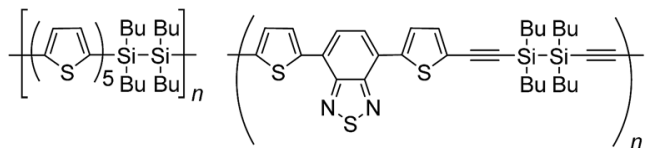

\section{DS5T}

$\lambda_{\max }=436 \mathrm{~nm} \quad \lambda_{\max }=487 \mathrm{~nm}$

$\mathrm{PCE}=0.11 \%$

$\mathrm{PCE}=0.25 \%$

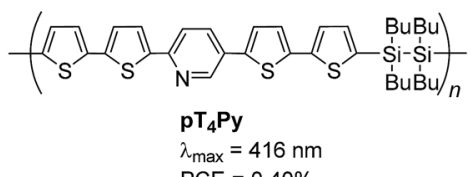

$\lambda_{\text {max }}=416 \mathrm{~nm}$

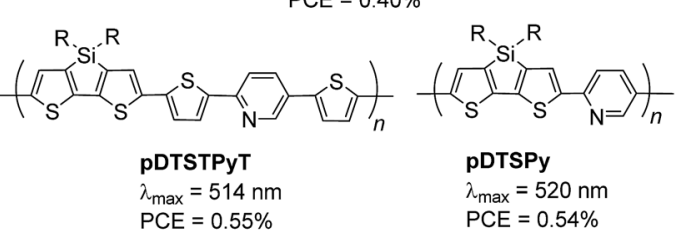

$\mathrm{R}=$ 2-ethylhexyl

Chart 1 Previously reported organosilicon polymers as DSSC materials.

Si-O-Ti linkage to suppress the DSSC performance (Fig. 1(2)). ${ }^{6}$ Py polymers pDTSTPyT and pDTSPy without disilane bonds were then examined and found to show slightly higher PCEs of $0.55 \%$ and $0.54 \%$, respectively. ${ }^{7}$

Recently, we introduced disilanobithiophene (DSBT) as a new donor component of conjugated D-A polymers, and demonstrated its application to bulk hetero-junction polymer solar cells. ${ }^{8}$ In this paper, we report the synthesis of new D-A polymers with DSBT donor and pyridine or pyrazine (Py or $\mathrm{Pz}$ ) acceptor. Their optical properties and applications to DSSCs are described. The photochemically generated silyl radicals in DSBT would undergo facial recombination to recover the $\mathrm{Si}-\mathrm{Si}$ bond, thereby avoiding their addition to the $\pi$-conjugated units. The Py and Pz units would coordinate to the Lewis acid center of $\mathrm{TiO}_{2}$, thus making multiple binding of the polymer chain to the surface possible. We investigated also a homo polymer of DSBT to understand the roles of the Py and Pz units.

\section{Experimental $\dagger$}

\section{Synthesis of pDSBT}

A mixture of $325 \mathrm{mg}(0.405 \mathrm{mmol})$ of DSBTBrSn, $18.5 \mathrm{mg}$ $(5.0 \mathrm{~mol} \%)$ of $\mathrm{Pd}_{2}(\mathrm{dba})_{3}, 24.7 \mathrm{mg}(20.0 \mathrm{~mol} \%)$ of $\mathrm{P}(o \text {-tol })_{3}$, and $8 \mathrm{~mL}$ of toluene was heated at $75^{\circ} \mathrm{C}$ for $96 \mathrm{~h}$. As a usual workup process, an aqueous solution of sodium $\mathrm{N}, \mathrm{N}$-diethyldithiocarbamate trihydrate was added to the reaction mixture, and the mixture was heated at $80{ }^{\circ} \mathrm{C}$ for $2 \mathrm{~h}$. The organic layer was separated and washed with water, 3 vol\% acetic acid aqueous solution, and water again in that order. The organic layer was dried over anhydrous magnesium sulfate and the solvent was evaporated. The residue was reprecipitated from toluene/methanol and then toluene/ethanol to give $209 \mathrm{mg}$ (92\% yield) of pDSBT as a purple solid. Mp 209-258 ${ }^{\circ} \mathrm{C} .{ }^{1} \mathrm{H}$ NMR (in $\left.\mathrm{C}_{6} \mathrm{D}_{6}\right): \delta=0.68-1.17(20 \mathrm{H}, \mathrm{m}, n \mathrm{Hex}), 1.23-1.45(24 \mathrm{H}, \mathrm{m}$, $n \mathrm{Hex}), 1.51-1.71(8 \mathrm{H}, \mathrm{m}, n \mathrm{Hex}), 7.47(2 \mathrm{H}, \mathrm{br} \mathrm{s}$, thiophene).
${ }^{13} \mathrm{C}$ NMR (in $\mathrm{C}_{6} \mathrm{D}_{6}$ ): $\delta=13.48,14.23,16.25$ ( $n \mathrm{HexSiO}$ ), 22.99, 23.47 ( $n$ HexSiO), 25.46, 31.84, 33.28 ( $n$ HexSiO), 33.69, 130.76, 135.94 (2C), 145.09 .

\section{Synthesis of pDSOBT}

A mixture of $222 \mathrm{mg}(0.272 \mathrm{mmol})$ of DSOBTBrSn, $12.5 \mathrm{mg}$ $(5.0 \mathrm{~mol} \%)$ of $\mathrm{Pd}_{2}(\mathrm{dba})_{3}, 16.5 \mathrm{mg}(20.0 \mathrm{~mol} \%)$ of $\mathrm{P}(o \text {-tol })_{3}$, and $7 \mathrm{~mL}$ of toluene was heated at $75{ }^{\circ} \mathrm{C}$ for $96 \mathrm{~h}$. After usual workup as above, the residue was reprecipitated from toluene/methanol to give $98.7 \mathrm{mg}$ (63\% yield) of pDSOBT as a red solid. Mp 110-158 ${ }^{\circ} \mathrm{C} .{ }^{1} \mathrm{H}$ NMR (in $\mathrm{C}_{6} \mathrm{D}_{6}$ ): $\delta=0.86-1.03$ (20H, m, $n$ Hex), 1.22-1.43 (24H, m, $n$ Hex), 1.51-1.68 (8H, m, $n$ Hex), $7.43(2 \mathrm{H}, \mathrm{br}$ $\mathrm{s}$, thiophene). ${ }^{13} \mathrm{C}$ NMR (in $\mathrm{C}_{6} \mathrm{D}_{6}$ ): $\delta=14.29,16.21,22.93,23.46$, 31.92, 33.28, 131.08, 137.83, 140.31, 145.39.

Alternatively, pDSOBT was prepared by oxidizing pDSBT. A solution of $49.6 \mathrm{mg}$ ( $0.446 \mathrm{mmol})$ of trimethylamine $N$-oxide dihydrate in $50 \mathrm{~mL}$ of toluene was dehydrated by azeotropic distillation of $10 \mathrm{~mL}$ of toluene. To this was added $81.5 \mathrm{mg}$ of pDSBT at room temperature, and the mixture was heated to reflux overnight. After hydrolysis with water and evaporation of the solvent from the organic layer, the residue was reprecipitated from toluene/methanol to give pDSOBT as a red solid nearly quantitatively. Its ${ }^{1} \mathrm{H}$ NMR spectrum was consistent with that obtained by the polymerization of DSOBTBrSn.

\section{Synthesis of DSBT-containing D-A polymers}

A mixture of $342 \mathrm{mg}(0.386 \mathrm{mmol})$ of DSBTSn, $91.6 \mathrm{mg}$ (0.387 mmol) of 2,5-dibromopyridine, $17.4 \mathrm{mg}(5.0 \mathrm{~mol} \%)$ of $\mathrm{Pd}_{2}(\mathrm{dba})_{3}, 23.5 \mathrm{mg}(20.0 \mathrm{~mol} \%)$ of $\mathrm{P}(o \text {-tol })_{3}$, and $10 \mathrm{~mL}$ of chlorobenzene was heated at $75{ }^{\circ} \mathrm{C}$ for $96 \mathrm{~h}$. After usual workup as was done for pDSBT, the residue was reprecipitated from toluene/methanol to give $203 \mathrm{mg}$ (84\% yield) of pDSBTPy as a red solid. Mp 64-87 ${ }^{\circ} \mathrm{C} .{ }^{1} \mathrm{H}$ NMR (in $\left.\mathrm{CD}_{2} \mathrm{Cl}_{2}\right): \delta=0.70-1.08(20 \mathrm{H}$, $\mathrm{m}, n \mathrm{Hex}), 1.16-1.48(32 \mathrm{H}, \mathrm{m}, n \mathrm{Hex}), 7.14-7.24(0.6 \mathrm{H}, \mathrm{br} \mathrm{m}$, homo-coupled DSBT), $7.42(0.7 \mathrm{H}$, br s, DSBT), $7.62(0.7 \mathrm{H}$, br s, DSBT), 7.67-7.76 (0.7H, br $\mathrm{m}$, pyridylene), $7.90(0.7 \mathrm{H}$, br $\mathrm{s}$, pyridylene), 8.01-8.09 $(0.2 \mathrm{H}$, br $\mathrm{m}$, terminal Br-pyridyl), 8.47-8.53 (0.2H, br m, terminal bromopyridyl), $8.85(0.7 \mathrm{H}, \mathrm{br}$ $\mathrm{s}$, pyridylene), $8.97(0.2 \mathrm{H}$, br $\mathrm{s}$, terminal bromopyridyl). ${ }^{13} \mathrm{C}$ NMR (in $\mathrm{C}_{6} \mathrm{D}_{6}$ ): $\delta=13.60,14.21,16.36$ ( $n \mathrm{HexSiO}$ ), 22.99, 23.53 ( $n$ HexSiO), 25.53, 31.88, 33.34 ( $n$ HexSiO), 33.75. No clear $\mathrm{sp}^{2}$ carbon signals were observed due to the broadening and the low solubility of the polymer.

Other DSBT-containing D-A type polymers were obtained in a fashion similar to that above. pDSBTTPyT was purified by reprecipitation from $o$-dichlorobenzene/methanol. Brown solid. Mp 201-211 ${ }^{\circ} \mathrm{C} .{ }^{1} \mathrm{H}$ NMR (in $\left.\mathrm{C}_{6} \mathrm{D}_{6}\right): \delta=0.83-1.75(52 \mathrm{H}, \mathrm{m}$, $n \mathrm{Hex}), 6.78-7.64(8 \mathrm{H}, \mathrm{br} \mathrm{m}$, aromatic protons), $8.80(1 \mathrm{H}, \mathrm{br} \mathrm{s}$, pyridylene). ${ }^{13} \mathrm{C}$ NMR (in $\mathrm{C}_{6} \mathrm{D}_{6}$ ): $\delta=13.58,14.19,22.98,25.52$, $31.87,33.70$. No clear $\mathrm{sp}^{2}$ carbon signals were observed due to the broadening and the low solubility of the polymer. pDSBTPz was purified by reprecipitation from hot toluene/methanol. Red solid. Mp 77-150 ${ }^{\circ} \mathrm{C}$. ${ }^{1} \mathrm{H}$ NMR (in $\left.\mathrm{CD}_{2} \mathrm{Cl}_{2}\right): \delta=0.80-1.10(20 \mathrm{H}$, $\mathrm{m}, n \mathrm{Hex}), 1.18-1.48$ (32H, m, $n \mathrm{Hex}), 7.11-7.26(0.4 \mathrm{H}, \mathrm{m}$, homocoupled DSBT) $7.70(2 \mathrm{H}$, br s, thiophene), $8.90(2 \mathrm{H}$, br s, pyrazine). ${ }^{13} \mathrm{C}$ NMR (in $\mathrm{C}_{6} \mathrm{D}_{6}$ ): $\delta=13.57,14.17,16.33$ ( $n \mathrm{HexSiO}$ ), 
22.97, 23.53 ( $n \mathrm{HexSiO}$ ), 25.53, 31.88, 33.32 ( $n \mathrm{HexSiO}$ ), 33.72. No clear $\mathrm{sp}^{2}$ carbon signals were observed due to the broadening and the low solubility of the polymer. pDSBTTPzT1 was purified by reprecipitation from hot toluene/methanol. Red solid. Mp 200-226 ${ }^{\circ} \mathrm{C} .{ }^{1} \mathrm{H}$ NMR (in $\mathrm{C}_{6} \mathrm{D}_{6}$ ): $\delta=0.86-1.73(74 \mathrm{H}, \mathrm{m}, n \mathrm{Hex}$ ), 2.75-2.89 $\left(4 \mathrm{H}, \mathrm{m}, \mathrm{CH}_{2}\right.$ on thiophene), $7.32(2 \mathrm{H}, \mathrm{br}$ s, DSBT thiophene), $7.56(2 \mathrm{H}, \mathrm{s}$, thiophene), $8.64(2 \mathrm{H}, \mathrm{s}$, pyrazine $)$. ${ }^{13} \mathrm{C}$ NMR (in $\mathrm{C}_{6} \mathrm{D}_{6}$ ): $\delta=13.52,14.22,14.25,16.39$ ( $\left.n \mathrm{HexSiO}\right)$, 22.29, 22.30, 23.55 ( $n$ HexSiO), 25.52, 29.61, 30.14, 30.82, 31.89, 32.05, 33.36 ( $n$ HexSiO), 33.73, 128.67, 132.96, 134.31, 135.23, 135.33, 139.64, 139.91, 141.41, 146.02, 146.32. pDSBTTPzT2 was purified by reprecipitation from hot chlorobenzene/ethyl acetate. Brown solid. Mp 216-248 ${ }^{\circ} \mathrm{C} .{ }^{1} \mathrm{H}$ NMR (in THF- $\mathrm{d}_{8}$ ): $\delta=0.70-1.99(74 \mathrm{H}, \mathrm{m}, n \mathrm{Hex}), 2.93-3.16\left(4 \mathrm{H}, \mathrm{br} \mathrm{m}, \mathrm{CH}_{2}\right.$ on thiophene), 7.09-7.46 (4H, m, DSBT thiophene), $8.85(2 \mathrm{H}, \mathrm{br} \mathrm{s}$, pyrazine). ${ }^{13} \mathrm{C}$ NMR (in $\mathrm{C}_{6} \mathrm{D}_{6}$ ): $\delta=13.57,14.18,22.98,25.52$, $29.55,30.59,31.86,33.71$. No clear $\mathrm{sp}^{2}$ carbon signals were observed due to the broadening and the low solubility of the polymer.

\section{Results and discussion}

\section{Polymer synthesis}

We previously reported the synthesis of a DSBTbenzothiadiazole alternating polymer with butyl groups on the silicon atoms. ${ }^{8}$ In this study, we employed hexyl-substituted DSBT to increase the solubility of the polymers. Py-containing D-A polymers $\mathbf{p D S B T P y}$ and $\mathbf{p D S B T T P y T}$ were prepared by the Stille cross-coupling of DSBTSn with 2,5-dibromopyridine and 2,5-bis(5-bromo-2-thienyl)pyridine, respectively, as shown in Scheme 1 and Table 1. In those reactions, DSBTSn that was used as the monomer contained a small amount of the corresponding siloxane (DSOBT) that was formed during the preparation of DSBTBr and could not be separated from either DSBTBr or DSBTSn. The oxidation of DSBT units also occurred during the workup process of the polymers to an extent. The polymers were obtained as dark red solids and could be purified by reprecipitation. The lower yield of PDSBTTPyT than PDSBTPy was due to the formation of insoluble substances that were removed by filtration of the reaction mixture. Polymer molecular weights were determined by GPC (gel permeation chromatography) relative to polystyrene standards. GPC of PDSBTTPyT revealed a
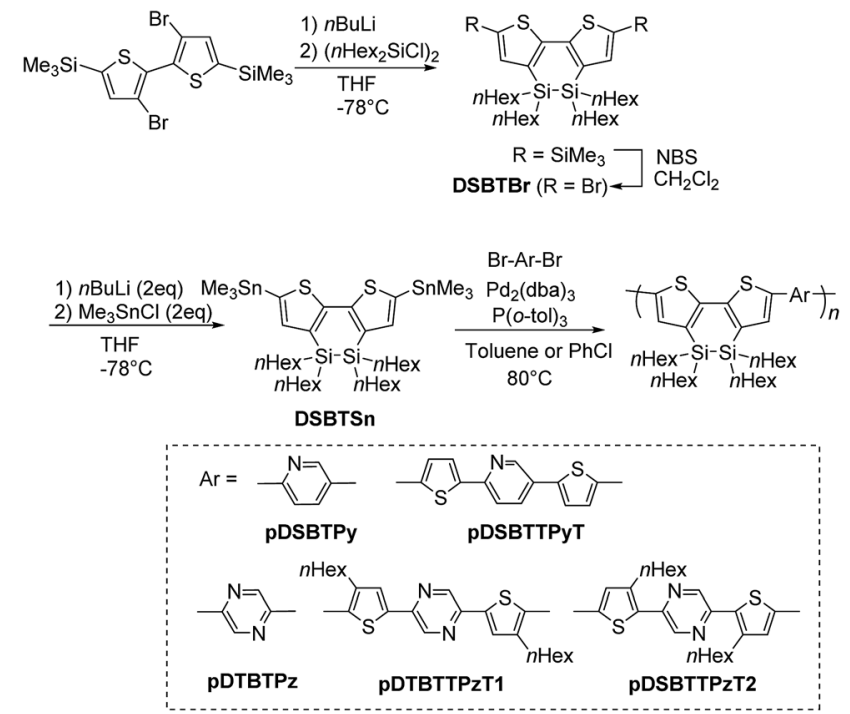

Scheme 1 Synthesis of DSBT-Py and DSBT-Pz polymers.

bimodal GPC profile with maxima at approximate molecular weights of 7300 and 167000 , in contrast to pDSBTPy that showed a monomodal GPC profile. However, the origin of the different GPC profiles of the polymers is not clear yet. A DSBT homo polymer (pDSBT) was also prepared by the Stille coupling of DSBTBrSn as a purple solid (Scheme 2).

Polymer structures were verified mainly by NMR measurements. $\dagger$ The ${ }^{1} \mathrm{H}$ and ${ }^{13} \mathrm{C}$ NMR spectra of pDSBTTPyT were consistent with the regular alternating structure presented in Scheme 1. In contrast, those of pDSBTPy were rather complex, indicating structural irregularity. Fig. 2 shows the ${ }^{1} \mathrm{H}$ NMR spectrum of pDSBTPy with possible assignment based on the ${ }^{1} \mathrm{H}-{ }^{1} \mathrm{H}$ COSY spectrum and comparison of the data with those of the monomers and related compounds, including pDTSPy and pDSBT. The spectrum revealed signals due to homo-coupled DSBT-DSBT units around $7.2 \mathrm{ppm}$. The incorporation ratio of the homo-coupled units was determined to be approximately $x / y=75 / 25$ (Chart 2) on the basis of the signal integration. Similar homo-coupling was observed in the synthesis of pDTSPy under the same conditions. ${ }^{7}$ The spectrum also revealed small signals ascribed to terminal bromopyridyl units. The molecular weight calculated based on the integration of the terminal

Table 1 Synthesis of DSBT-containing polymers

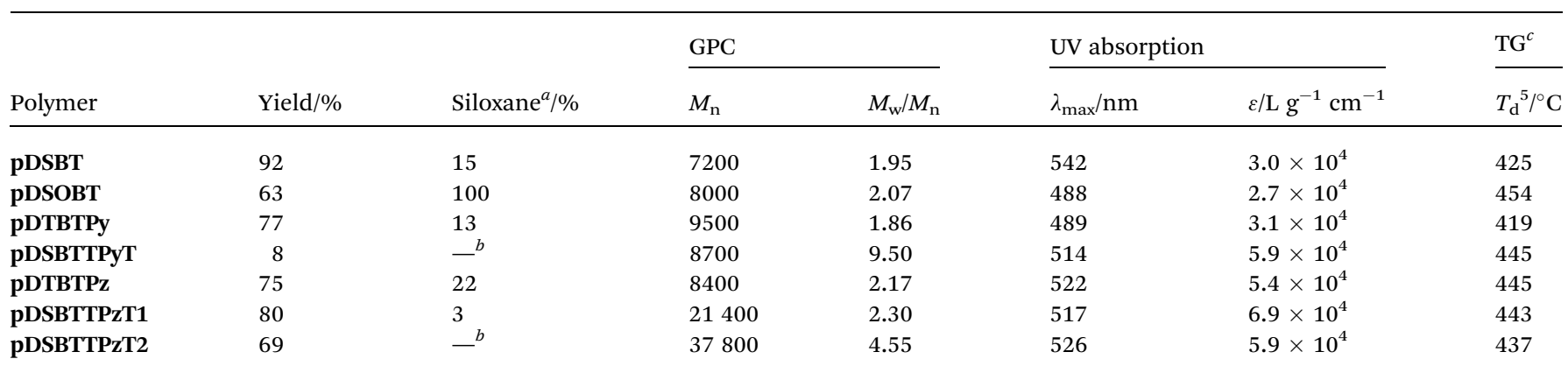

${ }^{a}$ Siloxane contamination in the backbone, based on ${ }^{13} \mathrm{C}$ NMR spectra. ${ }^{b}$ Could not be determined due to low solubility, but siloxane contamination could be detected by IR spectrum. ${ }^{c}$ In nitrogen at the heating rate of $10{ }^{\circ} \mathrm{C} \mathrm{min}{ }^{-1}$. 


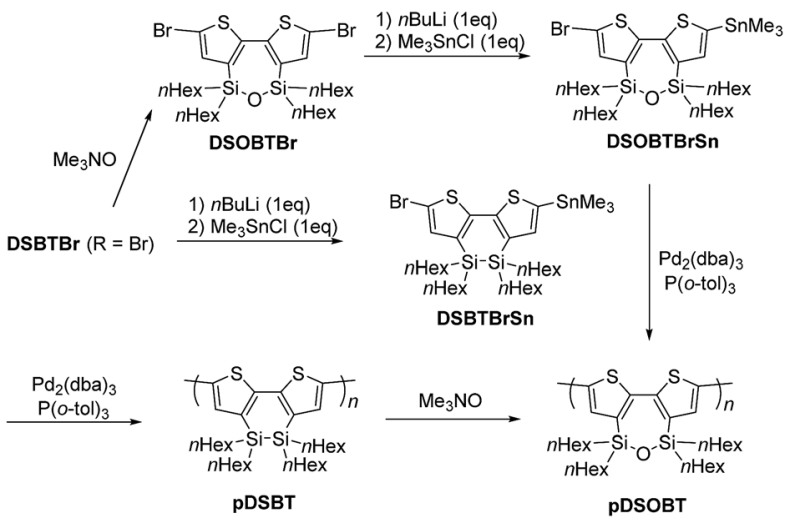

Scheme 2 Synthesis of DSBT homo polymer and its oxidation.

bromopyridyl protons was approximately 7000, in good agreement with that determined by GPC. The contamination ratio of siloxane units in pDSBTPy was determined from the intensities of the hexyl groups in the ${ }^{13} \mathrm{C}$ NMR spectra. The siloxane hexyl carbon signals were identified by comparison with those of pDSOBT that was prepared in two routes, as shown in Scheme 2. The broad Si-O stretching band around $1000 \mathrm{~cm}^{-1}$ in the IR spectra also indicated the existence of the siloxane bonds. For pDSBTTPyT, no homo-coupled units were detected by NMR analysis. Siloxane contamination in pDSBTTPyT was noted from the IR spectrum, but the ratio could not be determined from the ${ }^{13} \mathrm{C}$ NMR spectrum due to the low solubility of the polymer.

As shown in Table 1 and Fig. 3, the present polymers exhibited broad absorption bands in the UV-vis region, which were red-shifted from those of $\operatorname{DSBTBr}\left(\lambda_{\max }=356 \mathrm{~nm}\right)$ and TPyT (Chart 3), indicating the efficient conjugation between DSBT and Py or TPyT units. However, the absorption bands were blue-shifted from that of pDSBT. The twisting of the DSBT-Py bonds, which arose from the steric repulsion between thiophene and Py $\mathrm{C}-\mathrm{H}$ bonds, seemed to be responsible for the suppressed conjugation of pDSBTPy and pDSBTTPyT. In fact, computation on models at the B3LYP/6-31G(d) level of theory

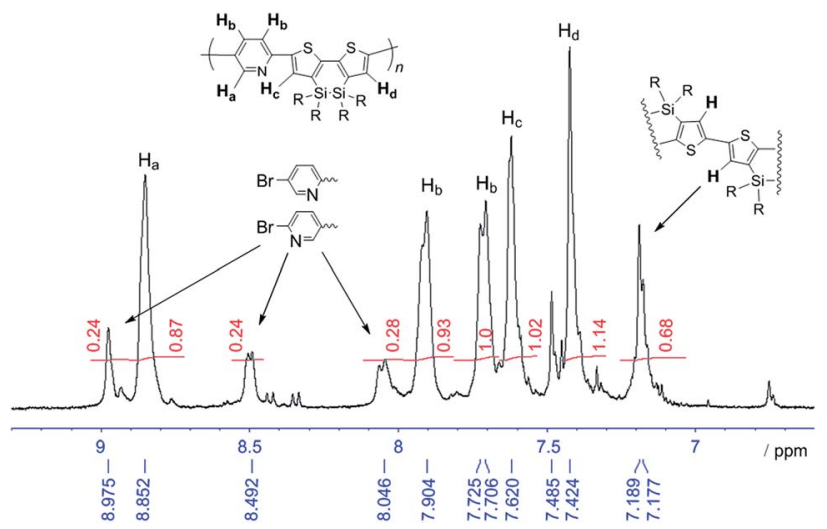

Fig. $2{ }^{1} \mathrm{H}$ NMR spectrum of pDSBTPy in $\mathrm{CD}_{2} \mathrm{Cl}_{2}$ with possible assignments ( $\mathrm{sp}^{2} \mathrm{CH}$ region).

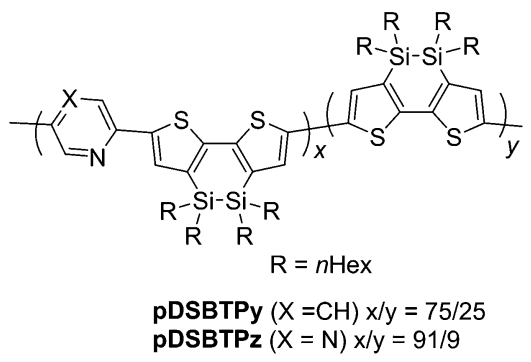

Chart 2 Detailed structures of pDSBTPy and pDSBTPz.

indicated a larger dihedral angle between the $\pi$-conjugated units of DSBT-Py than that of DSBT-DSBT, as shown in Fig. 4a. The rather weak $\mathrm{D}-\mathrm{A}$ interaction arising from the limited electron-accepting properties of Py would be also one reason for the blue-shifted absorption of the Py polymers. As depicted in Fig. $4 \mathrm{~b}$, both the HOMO and LUMO are delocalized over the DSBT-Py $\pi$-system, although the HOMO seems to be more DSBT-like judging from that the HOMO energy level is close to that of the DSBT unit. Similarly, an analogous DTS polymer pDTSPy has been reported to exhibit blue-shifted absorption $\left(\lambda_{\max }=520 \mathrm{~nm}\right)$ relative to that of a DTS homo polymer $\left(\lambda_{\max }=535 \mathrm{~nm}\right) .^{7}$ The absorption maxima of the present DSBT-polymers were also found at higher energies than those of the corresponding dithienosilole polymers, pDTSPy and pDTSTPyT $\left(\lambda_{\max }=519 \mathrm{~nm}\right)$. This may be due to the contamination of siloxane units in polymers pDSBTPy and pDSBTTPyT. It has been demonstrated that the conjugation in the siliconbridged bithiophene is suppressed in the order of DTS $^{9} \approx$ DSBT $^{\mathbf{1 0}}>$ DSOBT $^{\mathbf{1 1}}$ depending on the electronic effects of the silicon bridges and the planarity of the bithiophene units (Chart 3). Compared with DTS, DSBT possesses a more twisted bithiophene but exhibits stronger interaction between the silicon $\sigma^{*}$-orbital and the bithiophene $\pi^{*}$-orbital, thereby lowering LUMO and providing a similar degree of conjugation, as shown in Fig. 4 b. ${ }^{\mathbf{8}, 12}$ It is also seen that the Si-Si $\sigma$-orbital also contributes the HOMO to elevate it. It is also noteworthy that

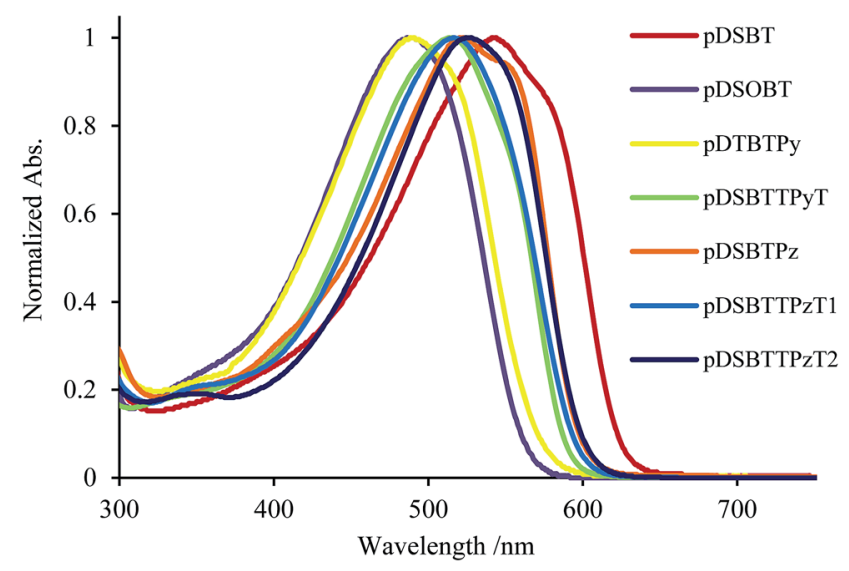

Fig. 3 UV-vis spectra of DSBT-containing polymers in dichlrorobenzene or chloroform (for pDSBTTPyT). 


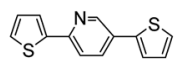

TPYT $\lambda_{\max }=352 \mathrm{~nm}$
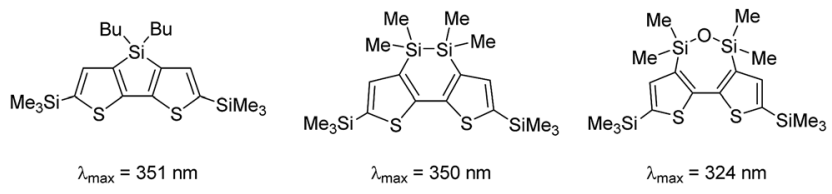

Chart 3 UV-vis absorption maxima of dithienylpyridine and dithienylpyrazine, and silicon-bridged bithiophenes.

compared with conventional polythiophenes, pDSBT showed expanded conjugation in a manner similar to pDTS $\left(\lambda_{\max }=\right.$ 545-561 nm), e.g., regio-regular poly(3-hexylthiophene) showed an absorption maximum at $458 \mathrm{~nm}^{13}$

We prepared Pz-containing polymers PDSBTPz, pDSBTTPzT1, and pDSBTTPzT2, with the expectation that replacement of the Py unit by a sterically less hindered $\mathrm{Pz}$ unit would enhance the polymer planarity (Scheme 1). For TPzT units, we introduced solubilizing hexyl groups. As expected, the $\mathrm{Pz}$ polymers showed red-shifted absorption maxima relative to those of model monomers TPzT1 and TPzP2 (Chart 3) and Py polymers pDSBTPy and pDSBTTPyT. Higher molecular weight of pDSBTTPzT1, and pDSBTTPzT2 may also be responsible for the red-shifted maxima from that of pDSBTTPyT. In fact, pDSBTTPzT2 with low molecular weight $\left(M_{\mathrm{n}}=3800\right.$ and $M_{\mathrm{w}} / M_{\mathrm{n}}$ $=12.2$ ) that was separated from the polymerization mixture as a solid soluble in ethyl acetate gave rise to a blue-shifted absorption maximum at $514 \mathrm{~nm} . \dagger$ However, this was still nearly the same as that of pDSBTTPyT with higher molecular weight $M_{\mathrm{n}}=8700$ and $M_{\mathrm{w}} / M_{\mathrm{n}}=9.5$, indicative of that Pz-containing polymers possess essentially the more enhanced conjugation. The introduction of alkyl groups on the polymers led to the increased solubility and thus the higher molecular weights of pDSBTTPzT1 and pDSBTTPzT2 than that of pDSBTTPyT. They showed monomodal profile in GPC analysis. (a)

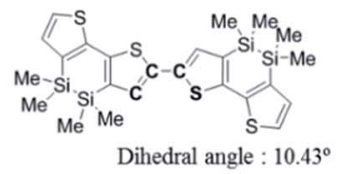<smiles>C[Si]1(C)c2ccsc2-c2cc(-c3ccc[nH]3)sc2[Si]1(C)C</smiles>

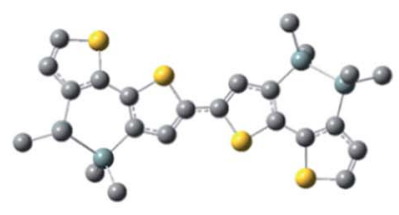
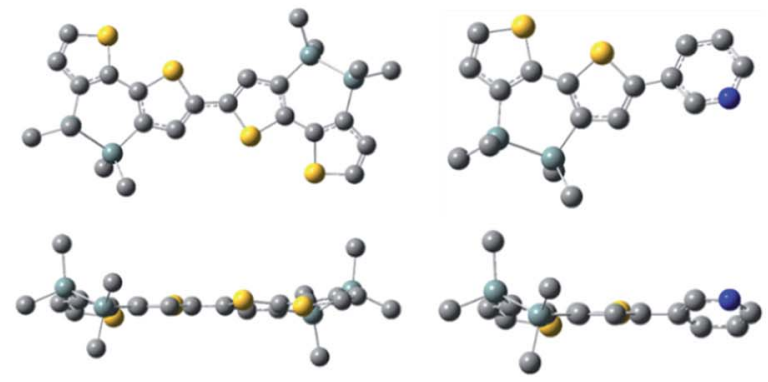

(b)
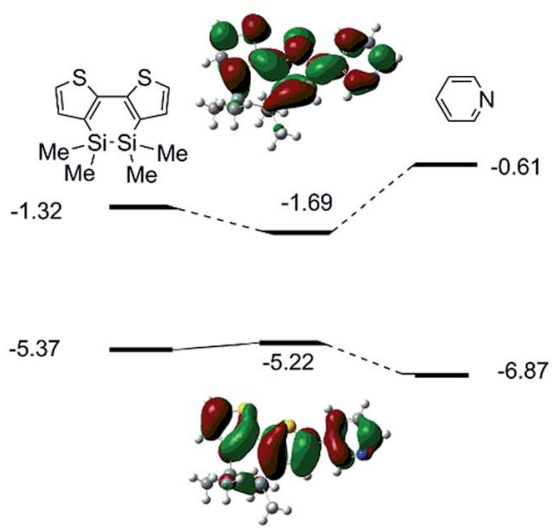

Fig. 4 (a) Dihedral angles and optimized geometries of DSBT-DSBT (left) and DSBT-Py (right) models with methyls on silicon atoms at B3LYP/6-31G(d) (hydrogen atoms are omitted for clarity).(b) HOMO and LUMO energy levels and profiles of DSBT-Py model.

The ${ }^{1} \mathrm{H}$ NMR spectrum of pDSBTPz confirmed the existence of the homo-coupled units, similarly to pDSBTPy. However, the incorporation ratio was only $x / y=91 / 9$ (Chart 2), which was much smaller than that of pDSBTPy. It is likely that the formation of sterically less hindered DSBT-Pz bonds proceeded more smoothly than the formation of DSBT-Py bonds. No

Table 2 DSSC $^{a}$ performance based on DSBT-containing polymers

\begin{tabular}{|c|c|c|c|c|c|c|}
\hline Polymer & Method $^{b}$ & Abs $\max ^{c} / \mathrm{nm}$ & $V_{\mathrm{oc}} / \mathrm{mV}$ & $J_{\mathrm{sc}} / \mathrm{mA} \mathrm{cm}^{-2}$ & $\mathrm{FF}$ & $\operatorname{PCE}(\eta) / \%$ \\
\hline \multirow[t]{2}{*}{ pDSBT } & $\mathrm{P}$ & 451 & 308 & 2.10 & 0.61 & 0.39 \\
\hline & $\mathrm{T}$ & 520 & 356 & 0.69 & 0.67 & 0.16 \\
\hline & $\mathrm{T}$ & 484 & 396 & 1.67 & 0.63 & 0.42 \\
\hline \multirow[t]{2}{*}{ pDSBTTPyT } & $\mathrm{P}$ & 468 & 380 & 3.11 & 0.63 & 0.74 \\
\hline & $\mathrm{T}$ & 475 & 392 & 1.34 & 0.66 & 0.35 \\
\hline \multirow{2}{*}{ pDSBTTPzT1 } & $\mathrm{P}$ & 482 & 396 & 2.21 & 0.64 & 0.56 \\
\hline & $\mathrm{T}$ & 489 & 432 & 2.28 & 0.68 & 0.67 \\
\hline \multirow[t]{2}{*}{ pDSBTTPzT2 } & $\mathrm{P}$ & 490 & 384 & 2.70 & 0.59 & 0.61 \\
\hline & $\mathrm{T}$ & 503 & 420 & 1.58 & 0.66 & 0.44 \\
\hline
\end{tabular}

${ }^{a}$ Cell structure: $\mathrm{FTO} /$ polymer-attached $\mathrm{TiO}_{2} / \mathrm{I}^{-} \cdot \mathrm{I}_{3}{ }^{-} / \mathrm{Pt} .{ }^{b} \mathrm{P}$ : under irradiation, $\mathrm{T}$ : in the dark. ${ }^{c}$ UV-vis absorption maximum of polymer-attached electrode. 

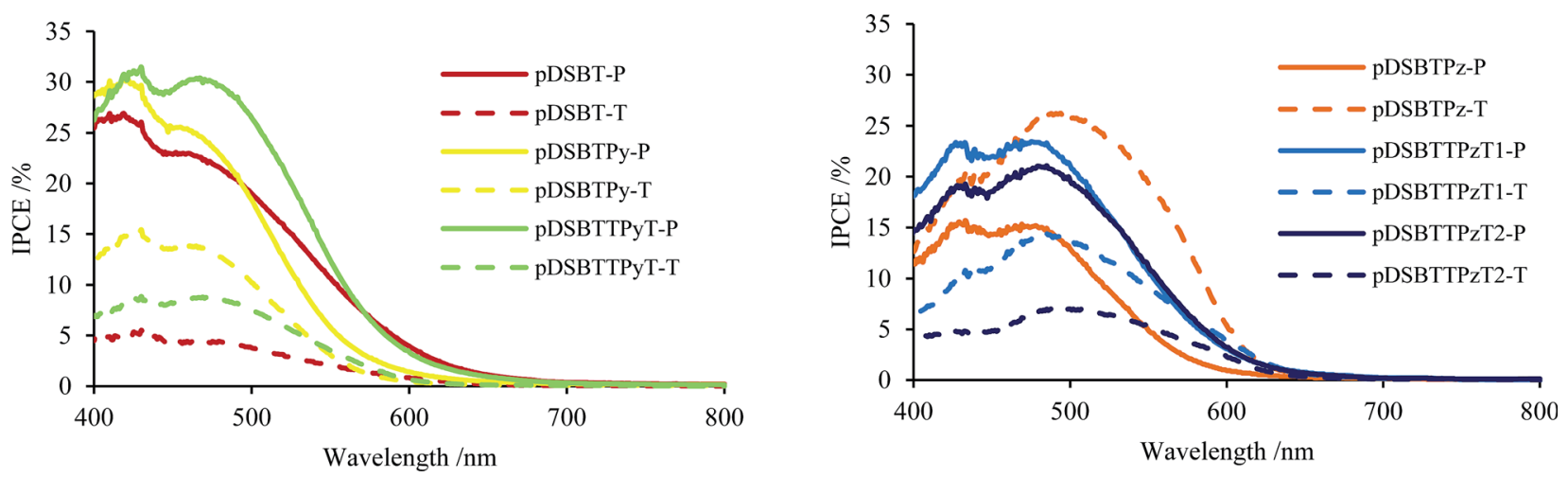

Fig. 5 IPCE spectra of $\mathrm{TiO}_{2}$ electrodes modified with DSBT-polymers ( $\mathrm{P}$ : photochemical conditions, $\mathrm{T}$ : thermal conditions).

signals due to the homo-coupled units were observed in the ${ }^{1} \mathrm{H}$ NMR spectra of pDSBTTPzT1 and pDSBTTPzT2.

The thermal stability of the polymers was investigated by thermogravimetric analysis (TGA) in nitrogen and the 5\% weight loss temperatures are listed in Table 1. Thermal decomposition occurred at temperatures exceeding $400{ }^{\circ} \mathrm{C}$, indicating the good thermal stability of the present polymers.

\section{Applications to DSSCs}

To prepare polymer-attached electrodes, $\mathrm{TiO}_{2} / \mathrm{FTO}$ electrodes were immersed in chloroform solutions of the present polymers $\left(3 \mathrm{mg} \mathrm{mL}^{-1}\right)$ in argon for $40 \mathrm{~min}$ under irradiation $(>400 \mathrm{~nm})$ (photochemical conditions) or in the dark (thermal conditions). Homo polymer pDSBT attached to the $\mathrm{TiO}_{2}$ surface efficiently under irradiation, providing a brown electrode. On the other hand, a lightly coloured electrode was obtained in the dark, indicating that the photochemical reactions of PDSBT occurred efficiently on the $\mathrm{TiO}_{2}$ surface, likely by forming $\mathrm{Si}-\mathrm{O}-\mathrm{Ti}$ bonds, although the thermal attachment of the polymer to $\mathrm{TiO}_{2}$ would be also involved to a certain extent. Alternating polymers with Lewis basic $\mathrm{Py}$ or $\mathrm{Pz}$ units could readily attach to the $\mathrm{TiO}_{2}$ electrodes under both photochemical and thermal conditions. No evident colour difference depending on the conditions was seen. However, the UV-vis spectra of the photochemically modified electrodes always showed blue-shifted absorption bands relative to those of the thermally modified electrodes (Table 2), indicating the photodegradation of chromophores. The Ti-O-Si bond formation would enhance the twisting of bithiophene units. The polymer-attached electrodes were then used for DSSCs with the FTO/polymer-attached $\mathrm{TiO}_{2} / \mathrm{I}^{-} \cdot \mathrm{I}_{3}{ }^{-} / \mathrm{Pt}$ structure. All the polymers exhibited sensitizing effects (Fig. 5 and 6 ) and the cell parameters are summarized in Table 2 . The cell with pDSBT showed higher performance when $\mathrm{TiO}_{2}$ was photochemically modified, probably due to the higher degree of polymer attachment. For the cells with Py- or Pz-containing polymers, however, no clear relationship between the performance and the attachment conditions was observed. For some of those cells, it is presumed that sufficient amounts of the polymers could be attached even in the dark. The highest performance was obtained using the electrode thermally modified by pDSBTPz.

\section{Quantum chemical simulation for polymer reaction}

To understand the anchoring reaction of DSBT with the $\mathrm{TiO}_{2}$ surface, we carried out quantum chemical calculations at the B3LYP/6-31+G(dp) level of theory on the Gaussian 09 program, and the results are presented in Fig. 7. The reaction was an exothermic one $\left(-50.1 \mathrm{kcal} \mathrm{mol}^{-1}\right)$, likely due to the formation of thermodynamically stable $\mathrm{Si}-\mathrm{O}$ bonds. The optimized geometries of DSBT and DSBT-attached $\mathrm{TiO}_{2}$ models indicate that the attachment enhances the twisting of the bithiophene
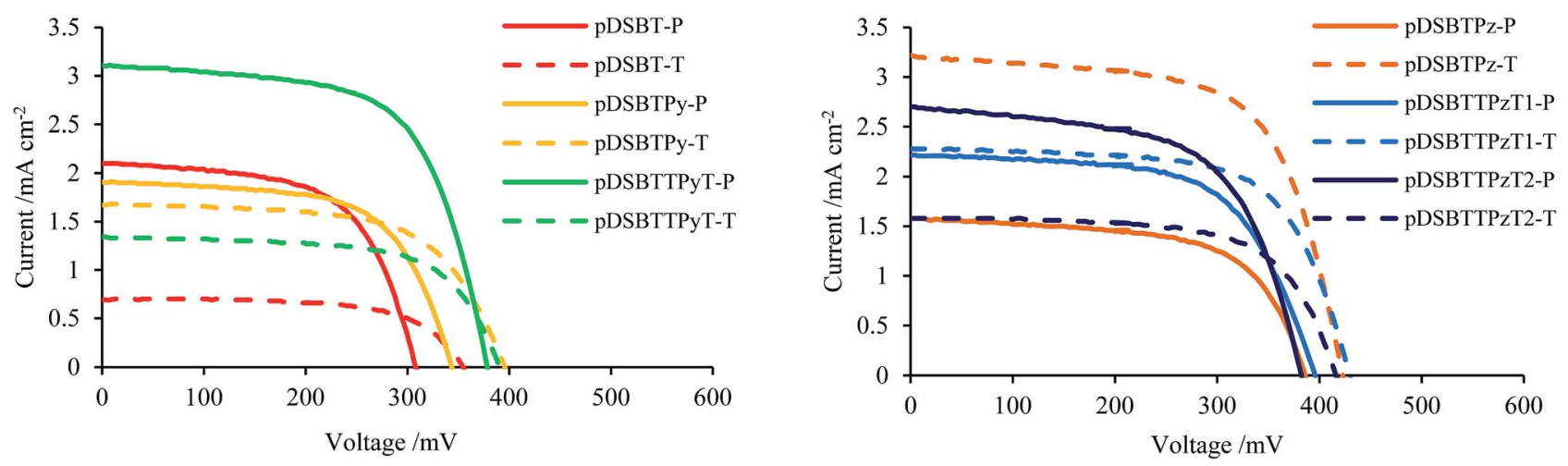

Fig. $6 \mathrm{I}-\mathrm{V}$ characteristics of DSSCs based on $\mathrm{TiO}_{2}$ electrodes modified with DSBT polymers (P: photochemical conditions, $\mathrm{T}$ : thermal conditions). 

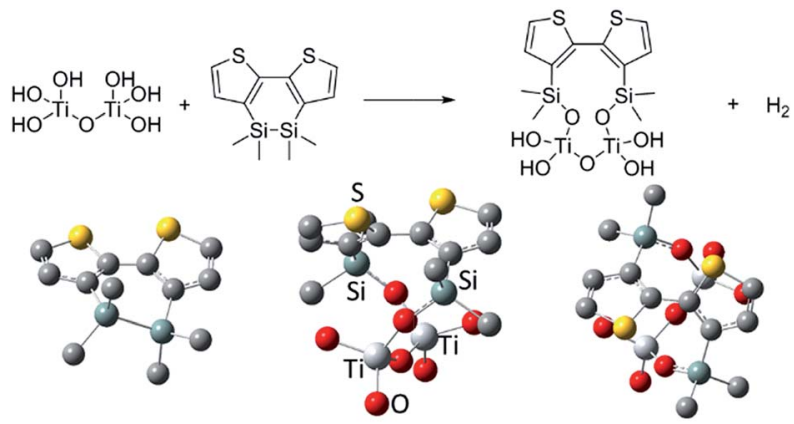

Fig. 7 Model reaction (top) and optimized geometries (bottom) of DSBT and top and side views of DSBT-attached $\mathrm{TiO}_{2}$ models (from left to right), derived from quantum chemical simulation at B3LYP/ $6-31+G(d p)$ (hydrogen atoms are omitted for clarity).

system in which the $\mathrm{S}-\mathrm{C}-\mathrm{C}-\mathrm{S}$ dihedral angle is increased from $19.1^{\circ}$ to $68.8^{\circ}$. This may be the reason for the blue-shifted absorption of the polymers upon interaction with the $\mathrm{TiO}_{2}$ surface even under thermal conditions.

\section{Conclusions}

In summary, we prepared new D-A polymers with DSBT as the donor and Py or Pz as the acceptor, and applied them to DSSCs. Although the device performance is still unsatisfactory, this is a new polymer system that is expected to modify inorganic oxide surfaces. Studies to explore polymer functionalities other than DSSC applications are in progress.

\section{Acknowledgements}

This work was supported by a Grant-in-Aid for Scientific Research (B) (no. 26288094) from the Ministry of Education, Culture, Sports, Science and Technology, Japan.

\section{Notes and references}

1 Y.-J. Cheng, S.-H. Yang and C.-S. Hsu, Chem. Rev., 2009, 109, 5868.
2 Y. Ooyama and Y. Harima, Eur. J. Org. Chem., 2009, 18, 2903.

3 (a) K. Kakiage, M. Yamamura, E. Fujimura, T. Kyomen, M. Unno and M. Hanaya, Chem. Lett., 2010, 39, 260; (b) M. Unno, K. Kakiage, M. Yamamura, T. Kogure, T. Kyomen and M. Hanaya, Appl. Organomet. Chem., 2010, 24, 247.

4 (a) J. Ohshita, J. Matsukawa, M. Hara, A. Kunai, S. Kajiwara, Y. Ooyama, Y. Harima and M. Kakimoto, Chem. Lett., 2008, 37, 316; (b) J. Ohshita, D. Tanaka, J. Matsukawa, T. Mizumo, H. Yoshida, Y. Ooyama and Y. Harima, Chem. Lett., 2011, 40, 87; (c) D. Tanaka, J. Ohshita, Y. Ooyama, T. Mizumo and Y. Harima, J. Organomet. Chem., 2012, 719, 30; (d) D. Tanaka, J. Ohshita, T. Mizumo, Y. Ooyama and Y. Harima, J. Organomet. Chem., 2013, 741-742, 97.

5 Y. Ooyama, S. Inoue, T. Nagano, K. Kushimoto, J. Ohshita, I. Imae, K. Komaguchi and Y. Harima, Angew. Chem., Int. Ed., 2011, 50, 7429.

6 (a) J. Ohshita and A. Kunai, Acta Polym., 1998, 49, 379; (b) A. Kunai, T. Ueda, K. Horata, E. Toyoda, I. Nagamoto, J. Ohshita, M. Ishikawa and K. Tanaka, Organometallics, 1996, 15, 2000; (c) J. Ohshita, D. Kanaya and M. Ishimkawa, J. Organomet. Chem., 1994, 468, 55.

7 D. Tanaka, J. Ohshita, Y. Ooyama and Y. Morihara, Polym. J., 2013, 45, 1153.

8 J. Ohshita, M. Nakashima, D. Tanaka, Y. Morihara, H. Fueno and K. Tanaka, Polym. Chem., 2014, 5, 346.

9 D.-H. Kim, J. Ohshita, K.-H. Lee, Y. Kunugi and A. Kunai, Organometallics, 2006, 25, 1511.

10 J. Ohshita, M. Nodono, H. Kai, T. Watanabe, A. Kunai, K. Komaguchi, M. Shiotani, A. Adachi, K. Okita, Y. Harima, K. Yamashita and M. Ishikawa, Organometallics, 1999, 18, 1453.

11 Y.-W. Kwak, I.-S. Lee, M.-K. Baek, U. Lee, H.-J. Choi, M. Ishikawa, A. Naka, J. Ohshita, K.-H. Lee and A. Kunai, Organometallics, 2006, 25, 48.

12 H. Kai, J. Ohshita, S. Ohara, N. Nakayama, A. Kunai, I.-S. Lee and Y.-W. Kwak, J. Organomet. Chem., 2008, 693, 3490.

13 J. Ohshita, K. Kimura, K.-H. Lee, A. Kunai, Y.-W. Kwak, E.-C. Son and Y. Kunugi, J. Polym. Sci., Part A: Polym. Chem., 2007, 45, 4588. 